\title{
Study of Association of C- Reactive Protein with Coronary Collateral Development
}

\author{
AAS Majumder, MF Karim, MA Rahman, MAFK Uddin \\ Department of Cardiology, National Institute of Cardiovascular Diseases, Dhaka
}

\begin{abstract}
:
Background: In vitro studies have shown that C-reactive protein (CRP) attenuates nitric oxide production and inhibits angiogenesis, which may result in impaired collateral development. The aim of this study was to investigate the association between CRP levels and the extent of coronary collaterals.

Keywords: $\quad$ Materials and methods: A total of 100 patients who had a stenosis of $\geq 95 \%$ in any major coronary Coronary artery artery in angiograms were included in the study. The CRP was measured from a venous blood sample with a high-sensitivity assay. Collaterals of the epicardial coronary arteries were then disease, C-reactive protein, Coronary colletarals studied and graded in a scale of 0 - 3 according to Rentrop classification.

Results: Mean age was 49.6 years and $86 \%$ were male. The mean CRP level was found 15.57 $\pm 12.85 \mathrm{mg} / \mathrm{L}$ in grade $0(n=25), 11.38 \pm 11.11 \mathrm{mg} / \mathrm{L}$ in grade $\mathrm{I}(\mathrm{n}=20), 9.22 \pm 10.15 \mathrm{mg} / \mathrm{L}$ in grade II $(n=34)$ and $8.97 \pm 8.44 \mathrm{mg} / \mathrm{L}$ in grade III $(n=21)$ collateral group. The mean CRP values reduced significantly $(p<0.05)$ as the Rentrop collateral grade increased which indicated that patients with a higher grade of collaterals significantly had less CRP. Subjects with a higher grade of collaterals were significantly less likely to have diabetes mellitus [odds ratio (OR): 0.53, 95\%; CI: 0.13, 0.91] or acute coronary syndrome [ odds ratio (OR) :0.67, 95\%; CL 0.43, 0.95] or higher CRP values [odds ratio (OR) 0.56 per 10 unit increase, 95\%; CL 0.22, 0.92] but they were more likely to have higher number of vessels with significant stenosis [odds ratio (OR) : 1.59 ; 95\% CI: 1.34, 1.87]. After adjusting for age, gender, clinical presentation with acute coronary syndrome, diabetes mellitus and the number of vessels with significant stenosis, each 10-unit increase in CRP values corresponded to 39\% reduced-odds of having a higher collateral grade ( OR: 0.61, 95\%: CL0.1 1,0.68).

Conclusion: It may be concluded that elevated levels of CRP are significantly and inversely associated with angiographically visible coronary collateral development assessed by Rentrop classification.
\end{abstract}

(Cardiovasc. j. 2010; 3(1) : 26-32)

\section{Introduction:}

Coronary collateral vessels are of clinical importance as they potentially limit the size of the myocardial infarction and the clinical sequels of coronary occlusion. ${ }^{1,2}$ In most cases, presence of coronary coiiaterals is a reliable indication of severe coronary artery disease. Well-developed coronary collaternals prevent development of ventricular pump dysfunction and thus responsible for better prognosis.

Patients with acute myocardial infarction. in whom thrombolytic therapy was unsuccessful may show subsequent improvement in regional and global wall motion if residual flow was improved by extensive collaterals. In 1989 Rentrop et al. ${ }^{3}$ suggested that presence of collaterals extend the time window for the beneficial effect of repeifusion therapy. However, there are significant differences in the degree of collateral development among individual patients.

Although severity of coronary stenosis, presence of diabetes mellitus, ${ }^{4}$ clinical presentation with stable angina pectoris ${ }^{5}$ were all suggested as potential determinants of collateral development, it is still unknown why some patients can develop sufficient collateral circulation while others do not.

Address of Correspondence : Prof. Abdullah Al Shafi Majumder, Department of Cardiology, National Institute of Cardiovascular Diseases, Dhaka, Bangladesh. E-mail: aasm@bangla.net 
The creative protein (CRP) is an inflammatory marker, "which is considered to be an independent risk factor for cardiovascular disease, and has prognostic importance in patients who have coronary artery disease. ${ }^{6}$ In addition, in vitro studies support a direct role for CRP in altering the atherothrombotic process. ${ }^{7}$

Ischemia induced coronary collateral growth is dependent on vascular endothelial growth factor and Nitric Oxide. ${ }^{8}$ Accumulating evidence suggests that CRP directly attenuates nitric oxide production and inhibits in vitro angioaenesis; ${ }^{9}$ the consequence of which may include impaired coronary collateral development

The current study was undertaken to assess the association of the CRP concentration with the extent of angiographically visible coronary collateral vessels in patients with high - grade coronary artery stenosis or occlusion.

\section{Materials and methods:}

This observational study was done in National Institute of Cardiovascular Diseases (NICVD), Dhaka, from May 2006 to April 2007. Patients who underwent coronary angiography and were found to have a stenosis of $>95 \%$ in any major coronary artery were included in the study. Patients undergoing PCI within the previous 30 days, patients with history of CABG, patients with acute or chronic infectious or inflammatory conditions were excluded from the study.

Coronary angiography and collateral scoring: Coronary angiography was performed by Judkin's method without the use of nitroglycerin. Percentage stenosis diameter was measured visually. The patients who fulfilled the inclusion criteria were included. Coronary angiograms of the patients were then reviewed and collaterals were graded according to Rentrop classification.

Grade 0 : Non-developed- no collaterals were visible.

Grade 1 : Less- developed- only side branches, but no major trunk, were visualized through collaterals.

Grade 2 : Well- developed-partial filling of the epicardial segment of the stenosed artery through collaterals.

Grade 3 : Complete filling of the epicardial segment.
In subjects with $>1$ collateral supplying the distal aspect of the diseased artery, the higher collateral grade was used. . In subjects with $>$ Iqualifying severely diseased vessel, the vessel with the higher collateral grade was chosen for analysis.

Clinical evaluation: A thorough clinical evaluation was done by clinical history and examination. Demographic characteristics such as age, sex and weight were noted. History suggestive of acute infectious diseases or inflammatory conditions was also taken. Laboratory investigations such as total and differential count of WBC and ESR were done to exclude acute infectious diseases or inflammatory conditions. Risk factors for coronary artery disease such as hypertension, diabetes, dyslipidaemia and smoking were noted.

$C$-reactive protein measurement: Venous blood samples were collected immediately following coronary angiography from each patient and was sent to the laboratory for CRP measurement. The CRP was measured with a high- sensitivity assay ( Abbott AxSym Random Access Multibatch Immunoassay Analyzer ). The operators of the CRP analysis were unaware of the patients' clinical and angiographic characteristics.

\section{Statistical analysis}

Data were expressed in frequency, percentage; mean \pm standard deviation as applicable. Chi-square test, ANOVA test or others were used for comparison between groups as applicable. The association between the clinical and therapy related-characteristics and the extent of collaterals were examined using univariate and multivariate regression model.

All data were analyzed by using computer based SPSS (statistical programme for social science) programme (version 11). p value $<0.05$ was considered significant.

\section{Results:}

The whole study population was divided into 4 groups based on their collateral grades . he CRP values were then plotted against respective group to assess the association between the CRP levels and the coronary collateral grades. Table I shows the age distribution of the study population. 
Table-I

Age distribution of the study population ( $n=100)$

\begin{tabular}{|c|c|c|c|c|c|c|c|c|c|}
\hline \multirow[t]{2}{*}{ Age in years } & \multicolumn{2}{|c|}{$\begin{array}{c}\text { Group I } \\
(\mathrm{n}=25)\end{array}$} & \multicolumn{2}{|c|}{$\begin{array}{c}\text { Group II } \\
(\mathrm{n}=20)\end{array}$} & \multicolumn{2}{|c|}{$\begin{array}{c}\text { Group III } \\
(\mathrm{n}=34)\end{array}$} & \multicolumn{2}{|c|}{$\begin{array}{c}\text { Group IV } \\
(\mathrm{n}=21)\end{array}$} & \multirow[t]{2}{*}{$\overline{\mathrm{P} \text { value }}$} \\
\hline & $\overline{\mathrm{n}}$ & $\%$ & $\overline{\mathrm{n}}$ & $\%$ & $\overline{\mathrm{n}}$ & $\%$ & $\bar{n}$ & $\%$ & \\
\hline$<40$ & 3 & 12.0 & 1 & S.0 & 2 & S.9 & 2 & $9 . \mathrm{S}$ & 0.786 \\
\hline $40-49$ & 10 & 40.0 & 8 & 40.0 & 14 & 41.2 & 7 & 33.3 & 0.946 \\
\hline $50-59$ & 9 & 36.0 & 9 & 45.0 & 14 & 41.2 & 8 & 38.1 & 0.934 \\
\hline$>$ S9 & 3 & 12.0 & 2 & 10.0 & 4 & 11.8 & 4 & 19.0 & 0.823 \\
\hline Total & $2 \mathrm{~S}$ & 100 & 20 & 100 & 34 & 100 & 21 & 100 & \\
\hline Mean \pm SD & \multicolumn{2}{|c|}{$49.5 \pm 8.0$} & \multicolumn{2}{|c|}{$50.5 \pm 6.9$} & \multicolumn{2}{|c|}{$496 \pm 7.8$} & \multicolumn{2}{|c|}{$51.0 \pm 7.2$} & $0.637 \mathrm{NS}$ \\
\hline
\end{tabular}

Group I: collateral grade 0; Group II: collateral grade 1; Group III: collateral grade 2; Group IV: collateral grade 3; P value reached from ANOVA test ; NS: not significant $(P>0.5)$

The mean age of the group I was $49.5 \pm 8.0$ years, group 2 was $50.5 \pm 6.9$ years, group 3 was $49.6 \pm 7.8$ years and group 4 was $51.0 \pm 13.2$ years. Analysis revealed no statistically significant mean age difference among the four groups.. Most of the patients $(86 \%)$ were male and remaining $(14 \%)$ were female.

Risk factors for ischaemic heart disease presented in the study population are analyzed in Table-III. Among group I patients, highest percentage had smoking (68.0\%) followed by hypertension ( $64.0 \%)$, diabetes mellitus (36.0\%) and dislipidaemia (20.0\%). In group II patients highest percentage had smoking (75.0\%) followed by hypertension (45.0\%), diabetes mellitus (45.0\%) and dyslipidaemia (20.0\%).

No statically significant ( $p>0.05$ ) difference of risk factors for CAD was found among the four group of patients except diabetes mellitus ( $\mathrm{P}=0.047$ ) which was most prevalent in group-1 followed by group 2, group 3 group 4 .

An ascending pattern of distribution of patients with stable angina was observed among the groups and it was statistically significant $(\mathrm{P}=0.046)$ indicating that subjects with a higher grade of collaterals were significantly more likely to have stable angina.

A significant $(\mathrm{p}=0.019)$ difference $\sim 40.0 \%$ of patients had stable angina in group I, group II, group III and group IV respectively

of distribution was found among the groups highlighting that patients with higher collateral grade were significantly less likely to have ACS. )

The value of CRP $(\mathrm{mg} / \mathrm{L}$ ) of each of the study patients was plotted against respective group ..The mean value of CRP of each group was then calculated and compared among the groups.

The mean CRP level was found $15.57 \pm 12.85 \mathrm{mg} / \mathrm{L}$ in group I, $11.38 \pm 11.11 \mathrm{mg} / \mathrm{L}$ in group II, 9.22 $10.15 \mathrm{mg} / \mathrm{L}$ in group III and $8.97 \pm 8.44 \mathrm{mg} / \mathrm{L}$ in group IV. The mean CRP values reduced significantly $(\mathrm{p}<0.05)$ as the Rentrop collateral grade increased which indicated that patients with a higher grade of collaterals significantly had less CRP.

Table-II

Distribution of the study population by risk factors $(n=100)$

\begin{tabular}{|c|c|c|c|c|c|c|c|c|c|}
\hline \multirow[t]{2}{*}{ Risk factors } & \multicolumn{2}{|c|}{$\begin{array}{c}\text { Group I } \\
(\mathrm{n}=25)\end{array}$} & \multicolumn{2}{|c|}{$\begin{array}{c}\text { Group II } \\
(\mathrm{n}=20)\end{array}$} & \multicolumn{2}{|c|}{$\begin{array}{c}\text { Group III } \\
(\mathrm{n}=34)\end{array}$} & \multicolumn{2}{|c|}{$\begin{array}{c}\text { Group IV } \\
(\mathrm{n}=21)\end{array}$} & \multirow[t]{2}{*}{$\mathrm{P}$ value } \\
\hline & $\overline{\mathrm{n}}$ & $\%$ & $\overline{\mathrm{n}}$ & $\%$ & $\overline{\mathrm{n}}$ & $\%$ & $\overline{\mathrm{n}}$ & $\%$ & \\
\hline Ilypertcnsion & 16 & 64.0 & 13 & 65.0 & 18 & 52.9 & 11 & 52.4 & $0.298^{\prime \prime}$ \\
\hline $\mathrm{DM}$ & 9 & 36.0 & 9 & 45.0 & 8 & 23.5 & 3 & 14.3 & $0.047^{\mathrm{s}}$ \\
\hline Smoking & 17 & 68.0 & 15 & 75.0 & 21 & 61.8 & 12 & 60.0 & $0.409^{\mathrm{Ns}}$ \\
\hline Dyslipidaemia & 5 & 20.0 & 4 & 20.0 & 13 & 38.2 & 6 & 28.6 & $0.241^{\mathrm{Ns}}$ \\
\hline
\end{tabular}

Group L Collateral grade 0; Group IL Collateral gradel; Group III: Collateral grade 2; Group IV: Collateral grade 3 ; P value reached from ANOVA test ; NS: not significant $(\mathrm{P}<0.05)$; S: significant $(\mathrm{P}>0.05)$ 
Table-III

Clinical presentation of the study population $(n=100)$.

\begin{tabular}{|c|c|c|c|c|c|c|c|c|c|}
\hline & \multicolumn{2}{|c|}{$\begin{array}{c}\text { Group I } \\
(\mathrm{n}=25)\end{array}$} & \multicolumn{2}{|c|}{$\begin{array}{c}\text { Group II } \\
(\mathrm{n}=20)\end{array}$} & \multicolumn{2}{|c|}{$\begin{array}{c}\text { Group III } \\
(\mathrm{n}=34)\end{array}$} & \multicolumn{2}{|c|}{$\begin{array}{l}\text { Group IV } \\
(\mathrm{n}=21)\end{array}$} & \multirow[t]{2}{*}{$\mathrm{P}$ value } \\
\hline & $\overline{\mathrm{n}}$ & $\%$ & $\overline{\mathrm{n}}$ & $\%$ & $\overline{\mathrm{n}}$ & $\%$ & $\overline{\mathrm{n}}$ & $\%$ & \\
\hline Stable angina & 5 & 20.0 & 7 & 36.0 & 14 & 38.0 & 8 & 40.0 & $0.046^{8}$ \\
\hline $\begin{array}{l}\text { Acute coronary } \\
\text { syndrome }\end{array}$ & 20 & 80.0 & 13 & 64.0 & 20 & 62.0 & 13 & 60.0 & $0.019^{\mathrm{s}}$ \\
\hline UAP & 5 & 20.0 & 6 & 30.0 & 6 & 17.8 & 6 & 28.6 & $0.781^{\mathrm{N} 8}$ \\
\hline NSTEMI & 4 & 16.0 & 4 & 20.0 & 5 & 16.7 & 5 & 28.6 & $0.438^{\mathrm{N}} \sim$ \\
\hline STEMI & 11 & 44.0 & 3 & 14.0 & 9 & 27.5 & 2 & 9.5 & $0.015^{\sim}$ \\
\hline Total & 25 & 100 & 20 & 100 & 34 & 100 & 21 & 100 & \\
\hline
\end{tabular}

Group I Collateral grade 0; Group II Collateral grade 1;Group III: Collateral grade 2 ;Group IV: Collateral grade 3 ;P value reached from chi square test ;NS: not significant $(\mathrm{P}>0.05)$. S: Significant $(\mathrm{P}<0.05$ )

Table IV

THE mean C-reactive protein of the study patients $(n=100)$

\begin{tabular}{cccccc}
\hline & $\begin{array}{c}\text { Group I(n=25) } \\
\text { Mean } \pm \text { SD }\end{array}$ & $\begin{array}{c}\text { Group II(n=20) } \\
\text { Mean } \pm \text { SD }\end{array}$ & $\begin{array}{c}\text { Group III(n=34) } \\
\text { Mean } \pm \text { SD }\end{array}$ & $\begin{array}{c}\text { Group IV(n=21) } \\
\text { Mean } \pm \text { SD }\end{array}$ & P value \\
\hline CRP & $15.57 \pm 12.85$ & $11.38 \pm 11.11$ & $9.22 \pm 10.15$ & $8.97 \pm 8.44$ & 0.042 \\
\hline
\end{tabular}

Group 1: Collateral grade 0; Group IL Collateral grade 1; Group III: Collateral grade 2; Group IV: Collateral grade 3 ; P value reached from ANOVA test ; NS: not significant $(\mathrm{P}>$.0.05) S: Significant $(\mathrm{P}<0.05)$

The level of CRP was exoressed in $\mathrm{mg} / \mathrm{L}$ and Rentrop collateral grade was ex $\mathrm{p}_{\mathrm{p}}$ ressed as $0,1,2$ and 3 . A significant negative correlation was found between .,GRP level Pd collateral grade. The value of Pearson's correlation coefficient was -0.2042. This is significant $(\mathrm{p}<0.05)$. Therefore, there was significant negative correlation between C-reactive protein with collateral grade in the study population (Figure 7).

The association between between the various clinical characteristics and the extent of the callatcrals was examined by using univariatc models (i.e. examining the association collateral formation and each characteristic, singularly In the univariate models, the presence of diabetes mellitus [odds ratio (OR): 0.53, 95\%; CI: 0.13, 0.91] clinical presentation with acute coronary syndrome [ odds ratio (OR) :0.67, 95\%; CI: 0.43, 0.95] and higher CRP values [ odds ratio (OR) 0.56 per 10 unit increase, 95\%; CL 0.22, 0.92] were significantly

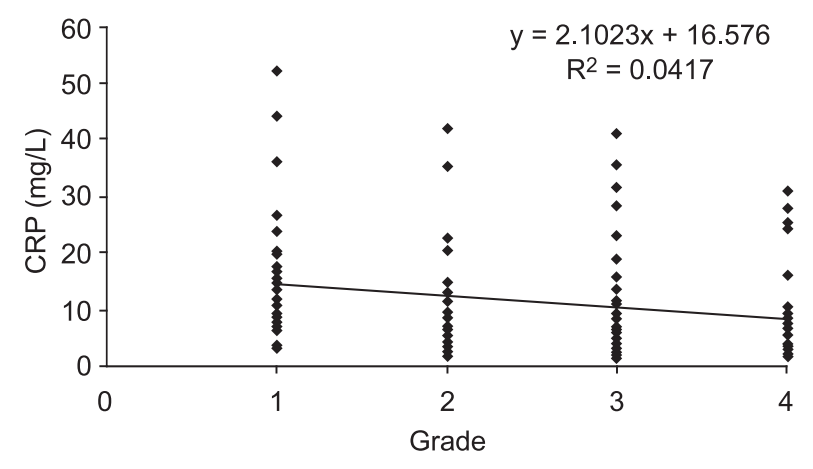

Fig.-1: The scatter diagram shows significant relationship ( $r=-0.2042)$ between CRP with collateral grade.

associated with a reduced-odds of having higher collateral grade compared with those who did not have these characteristics.

In contrast, the odds of having a higher collateral score was significantly higher among patients who had a higher number of significantly stenosed 
TabIe-Vll

Univariate and multivariate predictors of the extent of collaterals $(n=100)$.

\begin{tabular}{lcc}
\hline Characteristic & $\begin{array}{c}\text { Univariable Odds } \\
\text { ratio (95\% CI) }\end{array}$ & $\begin{array}{c}\text { Multivariable Odds } \\
\text { ratio (95\% CI) }\end{array}$ \\
\hline Age & $1.23(0.71,1.48)$ & $1.28(0.74,1.64)$ \\
Male & $0.77(0.31,1.78)$ & $2.51(0.45,3.97)$ \\
Smoking & $0.36(0.07,1.70)$ & $0.87(0.232 .92)$ \\
Hypertension & $1.19(0.43,1.82)$ & $1.52(0.59,2.37)$ \\
Diabetes mellitus & $0.53(0.13,0.91)$ & $0.37(0.20,1.70)$ \\
$\begin{array}{l}\text { Clinical presentation with acute } \\
\text { coronary syndrome (versus stable } \\
\text { angina) }\end{array}$ & $0.67(0.43,0.95)$ & $0.24(0.00,5.36)$ \\
$\begin{array}{l}\text { Number of vessels with significant } \\
\text { stenosis (per one vessel increase })\end{array}$ & & $7.22(3.27,13.11)$ \\
C-reactive protein (per 10 unit & $1.59(1.34,1.87)$ & \\
increase ) & & $0.61(0.11,0.68)$ \\
\hline
\end{tabular}

From logistic regression models where all patients were classified as having Rentrop class 0 , 1,2 or 3 collateral. The multivariable model includes all characteristics shown in the table.

vessels, odds ratio (OR) was 1.59 with $95 \%$ CI 1.34 , 1.87. No significant association was observed with age, gender, smoking and hypertension

In the multivariate regression model, the association between the CRP and the Rentrop collateral grades persisted after adjusting for age, gender, clinical presentation with ACS, diabetes mellitus and the number of vessels with significant stenosis . (OR: 0.61, 95\% CI: 0.11, 0.68) where each 10-unit increase in CRP values corresponded to $39 \%$ reduced- odds of having a higher collateral grade ( OR: 0.61, 95\%: CI:0.11,0.68).

\section{Discussion:}

The mean CRP values reduced significantly $(p<0.05)$ as the Rentrop collateral grade increased in the respective group indicating that patients with a higher grade of collaterals were significantly more likely to have less C-reactive protein (CRP). This finding is similar with that of gulac et al. ${ }^{10}$

This study revealed significant negative correlation $(\mathrm{r}=-0.2040)$ between CRP and coronary collateral grades which suggested that elevated levels of CRP were significantly associated with impairment of coronary collateral formation. Gulac et al. ${ }^{10}$ had shown similar finding in their study.
C- reactive protein is a strong independent predictor of adverse cardiac events and death in patients with acute coronary syndrome, in patient with stable ischemic heart disease and in apparently healthy men and women. Increased levels of CRP are associated with endothelial dysfunction. ${ }^{11}$ Venugopal et al. ${ }^{12}$ demonstrated that CRP attenuates endothelial NO synthase (eNOS) expression and bio-activity in human aortic endothelial cells. Verma,S, et $\mathrm{al}^{12}$ reported that $\mathrm{CRP}$, at concentrations known to predict adverse vascular events, directly quenches the production of the NO, and inhibits in vitro angiogenesis. They extended their findings by demonstrating that NO is required for bone marrow- derived endothelial progenitor cell ( EPC)- induced angiogenesis, and CRP directly inhibits EPC differentiation, survival and angiogenic function, in part by attenuating the EPC eNOS expression. ${ }^{13}$ Besides its central importance in angiogenesis, $\mathrm{NO}$ is likely to play a fundamental role in the acute modulation of collateral circuit vasomotor tone such that NO-mediated increases in vascular conductance allows for greater collateral dependent blood flow. ${ }^{14}$ Thus it is likely that the impaired collateral 
development in patients with elevated CRP levels may be related to CRP mediated endothelial dysfunction and attenuation of NO release.

In the present study, it was evident that there was no correlation between the age and CRP. So, age did not have any influence on the level of CRP.

In the univariate model, we observed that subjects with higher collateral grade were less likely to have diabetes indicating that diabetes was associated with poor collateralization. This result is consistent with that of Abaci et al. ${ }^{15}$ \& Islam $\mathrm{M}^{4}$ where they showed that diabetic persons had developed less coronary collateral vessels than non diabetic. Indeed, elevated CRP had been shown to predict poor cardiovascular outcome in patients with impaired glucose metabolism. ${ }^{16}$ It is therefore, reasonable to assume that the hyperglycemic state in diabetes could serve to exaggerate the detrimental effects of CRP on collateral development.

Chowdhury, $\mathrm{AW}^{5}$ showed progressively higher prevalence of collateral vessels with increasing number of coronary arterial involvement by atherosclerosis . Similar result we observed in our study as univariate model depicted that the odds of having higher collateral grade was higher among patients who had higher number of vessels with significant stenosis

In our study, higher levels of CRP was significantly associated with having lower col teral grade. This finding is also supported by Gulac et $\mathrm{al}^{10}$ Verma, S et $\mathrm{aL}^{9}$ where they addressed the mechanism of CRP induced collateral impairment . Collateral response of an individual patient is a complex mixture of two closely linked processes, namely angiogenesis and arteriogenesis. Verma S et al. ${ }^{9}$ stated that CRP, at concentration known to predict adverse vascular events, directly quenches the production of $\mathrm{NO}$ and inhibits in vitro angiogenesis.

Our findings indicated that elevated levels of CRP were associated with a significant impairment of coronary collateralization. Given the beneficial effects of well-developed collateral arteries on cardiovascular prognosis, our findings are consistent with the postulated idea that higher degree of inflammation may worsen the cardiovascular outcomes.

\section{Conclusion:}

It may be concluded that elevated levels of CRP are significantly and inversely associated with angiographically visible coronary collateral development assessed by Rentrop classification. The possible anticollaterogenic effect of CRP may partially contribute to adverse cardiovascular outcome associated with higher levels of this inflammatory marker. Our findings may raise the question that whether treatment strategies targeting CRP may improve collateral formation.

\section{References:}

1. Cohen M, Rentrop KP. Limitation of myocardial ischemia by collateral circulation during controlled coronary occlusion in human subject; a prospective study. Circulation 1986; 74 ; 469-76.

2. Coggins M, Sklenar J, Le E, Wei K, Linder JR, Kaul S. Non- invasive prediction of ultimate infarct size at the time of acute coronary occlusion based on the extent and magnitude of collateral derived myocardial blood flow. Circulation 2001; 104 ;2471-7.

3. Rentrop KP, Feit F, Sherman W. Late thrombolytic therapy preserves left ventricular function in patients with collateralized total coronary occlusion: primary end point findings of the second Mount Sinai - New York University Reperfusion Trial. JAm Coll Cardiol1989; $14 ; 59-64$.

4. Islam AEMM, Majumder AAS, Jalaluddin M. Angiographic pattern of coronary collaterals in diabetic patients. Bangladesh Heart Journal 2004; 19 ; 1; 25-8.

5. Chowdhury, AW. Study of coronary collaterals in different coronary syndromes by selective coronary arteriography. MD Cardiology Thesis 1998; NICVD, Bangladesh.

6. Biasucci. LM. ' CDC/AHA workshop on markers of inflammation and cardiovascular disease. Clinical use of inflammatory markers in patients with cardiovascular diseases: A background paper. Circulation 2004; 110 ; 560-7.

7. Jialal I, Devaraj S, Venugopal SK. C- reactive protein; risk marker or mediator in atherothrombosis? Hypertension 2004; 44; 6-11.

8. Matsunaga T, Wartleir DC, Weihrauch DW, Moniz M, Tessmer J, Chilian WM. Ischemia induced coronary collateral growth is dependent on vascular endothelial growth factor and nitric oxide. Circulation 2000; 102 ; 3098-103. 
9. Verma S, Wang CH, Li SH, Domont AS, Fedak PW, Badiwala MV. A self fulfilling prophecy ;C-reactive protein attenuates nitric oxide production and inhibits angiogenesis. Circulation 2002; 106 ; 912-9.

10. Gulac S, Ozdemir AO, Maradit- Kremers H, Dincer I, Atmaca Y, Erol C. Elevated levels of C- reactive protein are associated with impaired coronary collateral development. European Journal of Clinical Investigation 2006 ; 36; 369-75.

11. Fichtlscherer S, Rosenburg G, Walter DH, Breuer S, Zeiher AM. Elevated C-reactive protein levels and impaired endothelial vasoreactivity in patients with coronary artery disease. Circulation 2000; 102; 1000-6

12. Venogopal SK, Devaraj S,Yuhana I, Shaul P, Jilal I. Demonstration that C-reactive protein decreases Enos expression and bio- activity in human aortic endothelial cells. Circulation 2002; 106; 1439-41.
13. Verma S, Kuliszewski MA, Li SH, Szmitko PE, Zucco L, Wang CH. C-reactive protein attenuates endothelial progenitor cell survival, differentiation and function : further evidence of a mechanistic link between Creactive protein and cardiovascular disease. Circulation 2004; 4; 2058-67.

14. Unthank JL. Nixon JC, Dalsing MC. Nitric oxide maintains dilation of immature and mature collaterals in rat hindlimb. $J$ Vasc Res 2002; 33; 471-9

15. Abaci A, Oguzhan A,Billinger M, Herren E, Wustmann K, Arinc H. Effect of diabetes mellitus on formation of coronary collateral vessels. Circulation 1999; 99; 2239-42

16. Rikder PM. Clinical application of C- reactive protein for cardiovascular disease detection and prevention. Circulation 2003; 107; 363-369. 